Cahiers $d u$ MONDE RUSSE

\section{Cahiers du monde russe}

Russie - Empire russe - Union soviétique et États indépendants

$56 / 4 \mid 2015$

Médiateurs d'empire en Asie centrale (1820-1928)

\title{
A.V. Černecov, Staraja Rjazan', Klad 2005 goda, [Staraja Rjazan' : le trésor de 2005]
}

\section{Michel Kazanski}

\section{Q OpenEdition}

\section{Journals}

Édition électronique

URL : http://journals.openedition.org/monderusse/8232

DOI : 10.4000/monderusse.8232

ISSN : $1777-5388$

\section{Éditeur}

Éditions de l'EHESS

\section{Édition imprimée}

Date de publication : 1 octobre 2015

Pagination : 800-802

ISBN : 978-2-7132-2507-9

ISSN : $1252-6576$

Référence électronique

Michel Kazanski, «A.V. Černecov, Staraja Rjazan', Klad 2005 goda, [Staraja Rjazan’ : le trésor de 2005] », Cahiers du monde russe [En ligne], 56/4 | 2015, mis en ligne le 01 octobre 2015, Consulté le 24 septembre 2020. URL : http://journals.openedition.org/monderusse/8232 ; DOI : https://doi.org/ 10.4000/monderusse.8232

Ce document a été généré automatiquement le 24 septembre 2020. 


\title{
A.V. Černecov, Staraja Rjazan', Klad 2005 goda, [Staraja Rjazan' : le trésor de 2005]
}

\author{
Michel Kazanski
}

\section{RÉFÉRENCE}

A.V. ČERNECOV, Staraja Rjazan', Klad 2005 goda, [Staraja Rjazan' : le trésor de 2005],

Saint-Pétersbourg - Moscou : Nestor-Istorija, 2014, 104 p.

1 Le site archéologique de Staraja Rjazan' contient les vestiges de la ville médiévale de Rjazan' (la ville actuelle de Rjazan' en Fédération de Russie a reçu son nom en 1778, elle s'appelait auparavant Perejaslavl'-Rjazanskij), dont la partie fortifiée est de 60 ha. La ville est mentionnée pour la première fois dans des chroniques russes en 1096. C'est la capitale d'une importante principauté russe, annexée par Moscou au XVI ${ }^{\mathrm{e}}$ siècle. La ville a été détruite en 1237 par les Tatars. Sa population d'alors est estimée à près de 8000 habitants. Les fouilles de ce site médiéval sont actuellement menées, sous la direction d'Aleksej Černecov, par l'Institut d'archéologie de l'Académie des sciences de Russie ${ }^{1}$. Son dernier livre est la publication d'un riche trésor de parures enfoui en 1237 lors de la chute de la ville et découvert en $2005^{2}$. C'est d'ailleurs déjà le seizième trésor découvert à Rjazan' de 1237. Il contenait notamment un collier avec des médaillons pendentifs, deux pendentifs temporaux et plusieurs éléments de décoration de tête. Ces objets étaient très probablement déposés dans un sac en cuir, dont des fragments ont subsisté.

Dans l'introduction (p. 5-14), les auteurs donnent un aperçu de l'histoire des recherches à Staraja Rjazan', en s'arrêtant spécialement sur les découvertes de trésors, dont ceux de 1822, 1970, 1992 et 2002 sont illustrés par des photographies. Un autre trésor a déjà fait l'objet d'une publication à part ${ }^{3}$. 
3 Dans le premier chapitre (p.15-25), E. Bulankina dresse le catalogue du trésor et présente une description détaillée des décors et des techniques de fabrication des objets, une indication de leur taille et de leur poids, ainsi que de l'état de leur conservation. Il faut noter que tous ces objets ont été restaurés par V. Ponsov et P. Kotelnikov.

4 Le contexte archéologique de la découverte est décrit dans le deuxième chapitre (p.57-68), rédigé par I. Strikalov. On y apprend que le trésor provient de la partie sud-est du site. Dans ce secteur de fouilles (chantiers $n^{\circ} 34,35$ et 37 ), environ 1500 mètres carrés ont été dégagés. Ainsi, on a appris que la partie sud-est de la ville a été bâtie à la fin du XII ${ }^{\mathrm{e}}$-début du XIII ${ }^{\mathrm{e}}$ siècle. Le trésor de 2005 provient du chantier $\mathrm{n}^{\circ} 37$, dans la cave d'une maison, détruite en 1237 pendant la prise de la ville par les Tatars.

5 Le troisième chapitre (p. 69-79) est écrit par A.Černecov. Il est consacré à l'étude stylistique et iconographique des pendentifs du collier et des pendentifs temporaux, qui sont les objets les plus remarquables du trésor de 2005, déjà abordés par le même auteur en $2007^{4}$. D'après leur analyse stylistique, A.Černecov a conclu que certains objets provenant des trésors de 1966, de 1970 et de 2005 ainsi que des fouilles de 2010 sont issus d'un même atelier et sont probablement l'œuvre d'un même artisan.

6 Le quatrième chapitre (p. 80-95), écrit par N. Åilina, présente la typologie des objets faisant partie du trésor. Selon N. Åilina, le trésor contient surtout des parures du XII ${ }^{\mathrm{e}}$ siècle, cependant quelques objets sont du premier tiers du XIII ${ }^{\mathrm{e}}$ siècle. N. Åilina propose également une reconstitution du costume féminin susceptible d'être paré de ces bijoux.

Dans la conclusion collective (p. 96-99) les auteurs, en plus de l'information sur les seize trésors déjà connus, communiquent des premières données sur le dix-septième trésor de Rjazan', découvert en $2013^{5}$.

En somme, le nouveau livre sur le trésor de Rjazan' est à la fois une très bonne publication de nouvelles découvertes archéologiques et une étude approfondie sur l'orfèvrerie médiévale russe.

\section{NOTES}

1. Voir à ce propos publié récemment A.V.Černecov, E.V. Bulankina, I.Ju. Strikalov, "Staraja

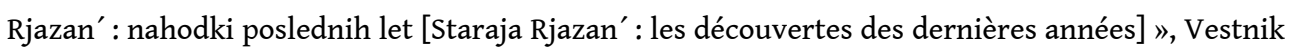
RGNF, N 1, 2014, p. 178-188.

2. Voir aussi les publications préliminaires de E.V. Bulankina, I.Ju. Strikalov, A.V.Černecov, «Klad 2005 g. iz raskopok na JuÂnom gorodišče [Le trésor de 2005 issu des fouilles menées dans la partie sud du site]" in A.V.Černecov, réd., Velikoe knjaÂestvo Rjazanskoe : istoriko-arheologi@eskie issledovanija i materialy [La Grande Principauté de Rjazan' : investigations historiques et archéologiques et documents], M., : 2005, 198-210.

3. V.P. Darkevič, A.L. Mongajt, Klad iz Staroj Rjazani [Le trésor de Staraja Rjazan'], M., 1978.

4. A.V.Černecov, «K harakteristike Starorjazanskogo klada $2005 \mathrm{~g}$. [Les caractéristiques du trésor de Staraja Rjazan' 2005] », Rossijskaja arheologija, № 1, 2007, p. 182-188. 
5. Černecov, Bulankina, Strikalov, «Staraja Rjazan' : nahodki poslednih let ».

\section{AUTEURS}

MICHEL KAZANSKI

Collège de France 